\title{
Changes in the Activity of Units of the Cat Motor Cortex with Rapid Conditioning and Extinction of a Compound Eye Blink Movement
}

\author{
Shuji Aou, ${ }^{a}$ Charles D. Woody, and Dorwin Birt \\ Mental Retardation Research Center, Brain Research Institute, UCLA Medical Center, Los Angeles, California 90024
}

Patterns of spike activity were measured in the pericruciate cortex of conscious cats before and after development of a Pavlovian conditioned eye blink response. Unit activity was tested with presentations of a click conditioned stimulus (CS) and a hiss discriminative stimulus (DS) of similar intensity to the click. Unit discharge in response to the CS increased after conditioning, but not after backward conditioning when conditioned reflexes (CRs) were not performed. Rates of spontaneous, baseline discharge were not increased after conditioning with respect to rates of discharge measured in the naive state. It appeared that an increase in the ratio of CS-elicited discharge to background activity, together with an increase in the number of units responding to the CS after conditioning, supported discrimination of the CS from the DS and performance of the conditioned blink response. This is the first detailed characterization of patterns of cortical neuronal discharge supporting the production of a rapidly conditioned Pavlovian response. Activation of units by the CS preceded the onset of the CR, supporting the hypothesis that the activity played a role in initiating the conditioned eye blink movement. Extinction with retention of performance of the CR was associated with perseverance of the increased unit discharge in response to the CS. Extinction with substantially reduced performance of the CR was associated with diminution of the unit response to the CS below levels found with conditioning.

Averages of patterns of spike activity elicited by the CS after conditioning showed components of discharge with onsets of 8-40 msec $\left(\alpha_{1}\right), 40-72 \mathrm{msec}\left(\alpha_{2}\right), 72-112 \mathrm{msec}$ $(\beta)$, and $>112 \mathrm{msec}(\gamma)$, corresponding to each of four separate excitatory EMG components of the compound blink CR. Each component increased in magnitude after conditioning, relative to levels found in the naive state. The finding that long- as well as short-latency components of unit activation increased after conditioning supported the hypothesis that generation of both long- and short-latency blink CRs in normal animals may depend significantly on neural circuitry and mechanisms within the motor cortex.

\footnotetext{
Received Mar. 18, 1991; revised Sept. 16, 1991; accepted Sept. 24, 1991.

This research was supported by HD 05958 and the Sasakawa Fund. We thank Drs. O. Hikosaka, Z. Karádi, and R. Pay for their comments on the manuscript.

Correspondence should be addressed to Dr. C. D. Woody, UCLA Medical Center, Room 58-232, NPI, 760 Westwood Plaza, Los Angeles, CA 90024.

a Present address: Department of Physiology, Faculty of Medicine, Kyushu University, Fukuoka 812, Japan.

Copyright (c) 1992 Society for Neuroscience $0270-6474 / 92 / 120549-11 \$ 05.00 / 0$
}

The motor cortex is thought to control the generation of movement (Woody and Engel, 1972; Evarts, 1981; Woody, 1982; Georgopoulos et al., 1988; Wise and Desimone, 1988), but it is not yet established how populations of units pattern their discharges to influence different temporal components of movements. Although there is evidence that the motor cortex supports learned movements performed with short latencies in response to Pavlovian conditional stimuli (CS) (Woody and Black-Cleworth, 1973; Woody et al., 1974), there is disagreement about the functional role of the motor cortex in the performance of longer-latency Pavlovian conditioned reflex, (CRs) (Thompson et al., 1984). To investigate these questions, we examined patterns of activation of units of the pericruciate cortex of cats before and after conditioning eye blink movements with short- and long-latency components. Comparisons were made between patterns of unit activity and patterns of EMG activity underlying performance of different components of the conditioned movement.

Unit activity to click CS and hiss discriminative stimulus (DS) was also compared among different behavioral states including adaptation, conditioning, extinction, and backward conditioning. Characteristic patterns of unit activity were established by combining averages of the activity of many singly recorded units. The significance of the CS and DS in eliciting CRs was assessed by separating units according to their receptivity to these stimuli (see Materials and Methods for definition). No previous assessment has been made of the role of cortical unit receptivity in rapidly acquired discriminative conditioning or of the relationship of short- and long-latency components of the firing patterns of cortical neurons to the components of concurrently performed blink CRs. The rate of acquiring these CRs was 10100 times faster than that using the same CS and unconditional stimulus (US) without addition of electrical stimulation of the hypothalamus (Woody et al., 1974; Hirano et al., 1987).

\section{Material and Methods}

Recordings from single units were obtained with glass microelectrodes pulled to tips of $<0.5 \mu \mathrm{m}$ (samples measured with scanning EM) from $\theta$-capillaries and filled with $3 \mathrm{M} \mathrm{KCl}$. Resistances of the electrodes (both barrels connected by a single $\mathrm{Ag} / \mathrm{AgCl}$ wire) ranged from 15 to 40 $M \Omega$. Electrodes were inserted by means of a guide tube into the pericruciate cortex of awake cats. The cats had been prepared earlier for recording as described previously in detail (Woody and Black-Cleworth, 1973). Stainless steel screws were implanted into the skulls of the animals using $\mathrm{Na}$ pentobarbital anesthesia $(35 \mathrm{mg} / \mathrm{kg}$, i.p.). The screws were used to fix the head to a stabilizing frame during later, awake training/recording sessions. Penicillin G $(225,000 \mathrm{U}$, i.m. $)$ and benza- 


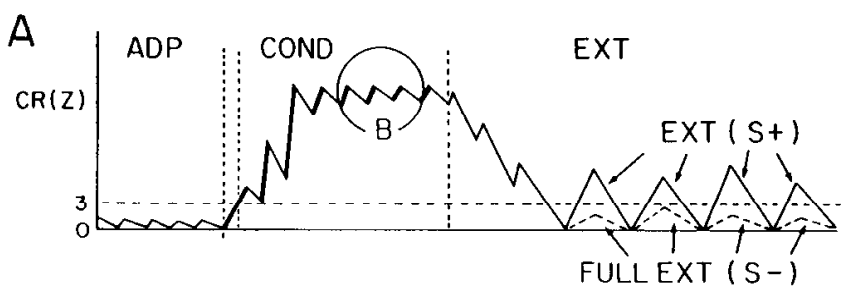

B

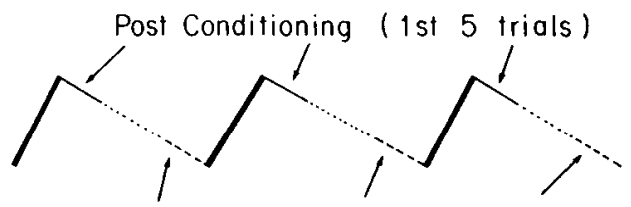

Partial Extinction (last 5 trials)
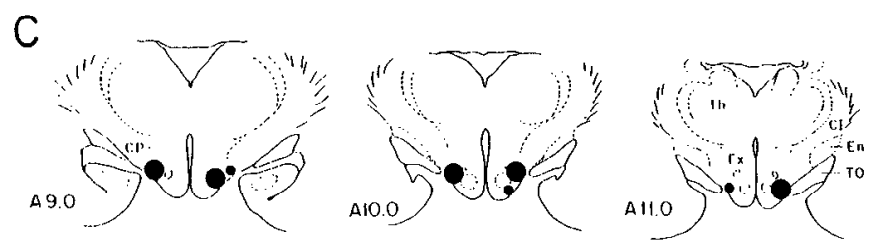

Figure 1. Training paradigms and behavioral states from which the data in this report were taken. $A: A D P$, adaptation (CS + DS); $C O N D$, conditioning (CS + US + HS . . + DS); EXT, extinction (CS + DS). $[E X T(S+)$, extinction with learning savings of CRs $\geq 3 Z$ above baseline EMG activity. FULL EXT $(S)$, extinction with learning savings of CRs $<3 Z$ above baseline EMG activity.] $B$, After conditioning, cxtinction trials (CS + DS alone, followed by reconditioning) were given to determine the patterns of unit activity associated with the acquired CR. The first five of these trials are designated Post Conditioning. The last five of these trials are designated Partial Extinction. $C$, Loci of the brain at which HS were delivered. (Some animals were stimulated on left as well as right side, each side unilaterally for separate unit recordings.) Large dots represent overlapping locations from more than one animal. $C I$, Internal capsule; $C P$, cerebral peduncle; $F x$, fornix; $E n$, entopeduncular nucleus; Th, thalamus; TO, optic tract. [Numbers are anterior stereotaxic planes in millimeters from interaural line, Snider and Niemer's (1961) atlas.]

thine penicillin $\mathrm{G}(75,000 \mathrm{U}$, i.m.) were given on the day of surgery, 3 d later during the recovery period, and at 1 week intervals thereafter, as needed. The animals were loosely restrained in cloth sleeves while their heads were fixed by previously implanted connectors to the metal frame used to hold the electrode assembly. The animals were continuously monitored by the investigators, and the experiments were discontinued at any sign of discomfort. The animals usually sat quietly throughout recording and approached the investigators readily before and after experimental sessions.

EMG activity was recorded bilaterally from orbicularis oculi and levator oris muscles as described earlier (Woody and Engel, 1972). After half-wave rectification and further amplification, EMG activity immediately preceding and following each stimulus presentation was analyzed using a PDP 11-44 computer. To characterize the nature of the response to click CS and hiss DS in different behavioral states, histogram averages of EMG data were constructed for individual cats and then combined to form grand averages across cats (e.g., see Fig. 3). The magnitude of activity in response to the stimuli was expressed in $Z$ scores relative to the standard deviation of the prestimulus baseline activity (Winer, 1971). Unless otherwise noted, the EMG activity that was used for analysis of each cat was taken from the left orbicularis oculi muscles. Running averages of every three responses $\left(R_{1-3}, R_{2-4}\right.$, etc.) were also made on line during experiments and displayed on a video terminal to permit continuous monitoring of eye blink performance elicited by the CS and DS.

Extracellular (EC) and intracellular (IC) unit activity were recorded with a Mentor high-impedance amplifier and stored on FM tape (Vetter 14 channel recorder; bandwidth: DC, $5000 \mathrm{~Hz}$ ). Analyses of EC activity were confined to spikes of $<20 \mathrm{mV}$ amplitude without an accompanying DC shift. Analyses of IC activity were confined to spikes of $>20 \mathrm{mV}$ amplitude and stable resting potentials after penetration (see Woody and Black-Cleworth, 1973; Woody et al., 1984). [The resting potentials of the IC recordings averaged $53 \mathrm{mV}$ with action potentials of up to 83 $\mathrm{mV}$ in amplitude (Aou et al., 1992).] As in earlier studies (Woody and Black-Cleworth, 1973; Woody et al., 1976), no significant differences were found between patterns of spike activity recorded intracellularly and those recorded extracellularly, and data were combined when making analyses of unit activity. The numbers of EC and IC units held long enough to measure patterns of activity during different behavioral states are shown in Table 1.

Grand averages of unit activity were made concurrent with the EMG averages across animals (see Fig. 3). The purpose was to define representative patterns of unit activity that could be related (or not) to temporally specific components of the conditioned behavioral response. Auditory receptivity was defined on the basis of increased single-unit activity ( $\geq 3 Z$ above background level) at any time in the $160 \mathrm{msec}$ period following CS or DS presentation. Spike occurrences were detected with a threshold discriminator (Frederick Haer) as shown in the raster display of Figure 2. Peristimulus time histograms of spike occurrences were made with reference to times of CS and DS occurrence for each cell that was studied. Then the data from the single units, each cell weighted equally, were averaged across animals to form the histograms used to characterize patterns of activity associated with production of the CR. Additional IC recordings were made to measure neuronal $\mathrm{mcm}$ brane properties as a function of conditioning (Aou et al., 1992). Withinanimal studies of unit activity before and after conditioning are reported in the following article (Aou et al., 1992), in relation to studies of neuronal membrane properties that might underly the changes.

It has been shown previously that layer V pyramidal tract (PT) cells respond selectively at short latencies to the click stimuli used as CS (Sakai and Woody, 1980) and that approximately $50 \%$ of all penetrations of cells of the pericruciate cortical region, using our techniques, are of layer $\mathrm{V}$ pyramidal cells. [As in an earlier investigation (Naito et al., 1969), all HRP-identified PT cells in those studies were found to be layer $\mathrm{V}$ pyramidal cells.] Thus, in the present studies, unit activity may be assumed to reflect, preferentially, the activity of layer $\mathrm{V}$ pyramidal cells.

Behavioral training. Conditioned (CS), unconditioncd (US), hypothalamic (HS), and discriminative (DS) stimuli were presented in timed sequences during trials of behavioral adaptation, conditioning, extinction, and delayed HS (Del HS; backward conditioning) paradigms (cf. Fig. 1 of Kim et al., 1983). Adaptation consisted of an initial period during which a click CS and hiss DS were presented $4.4 \mathrm{sec}$ apart (all cats were previously naive). Conditioning was accomplished by pairing click CS with glabella tap US and HS at interstimulus intervals (ISIs) of 570 and $10 \mathrm{msec}$, respectively. The hiss DS was presented $3.8 \mathrm{sec}$ after the HS. Extinction was accomplished by presenting clicks and hisses without US or HS as during adaptation. The delayed HS paradigm (Del HS) was a backward conditioning paradigm in which HS preceded each pairing of the CS and US (570 msec apart) by $2.5 \mathrm{sec}$. The interval between the HS and the DS was $4.47 \mathrm{sec}$. This paradigm served as an unpaired control for backward conditioning or pscudoconditioning. Intertrial intervals (ITIs) of $10 \mathrm{sec}$ were used for all paradigms. The 10 sec ITI facilitated the studies of unit activity and membrane properties.

Training consisted of (1) adaptation trials followed by repeated conditioning-extinction series and then repeated Del HS-extinction series or (2) adaptation followed by repeated Del HS-extinction series and then repeated conditioning-extinction series. (Not all animals received the entire series.) All testing of responses was done with presentations of click CS and hiss DS alone (as in the adaptation paradigm). Delivery of CS, US, HS, and DS during training and testing was controlled by means of the PDP 11-44 computer. The click CS was generated by a rectangular pulse of $1 \mathrm{msec}$ duration (delivered to a loudspeaker placed 1-2 feet in front of the animal). The clicks were of $70 \mathrm{~dB}$ intensity (General Radio Company dB meter type 1565-A) measured at the ears of the animals. The hisses were of comparable intensity to the clicks but longer duration (see Kim et al., 1983, for amplified earphone recordings of the stimuli). The glabella tap US was produced by means of a small metal rod driven electromechanically by a solenoid to strike a screw that was previously implanted in the glabella (for complete details, see Woody and Black-Cleworth, 1973; Woody et al., 1974). HS consisted of a train of four electrical stimuli delivered to the lateral hypothalamic region as described more fully below. 


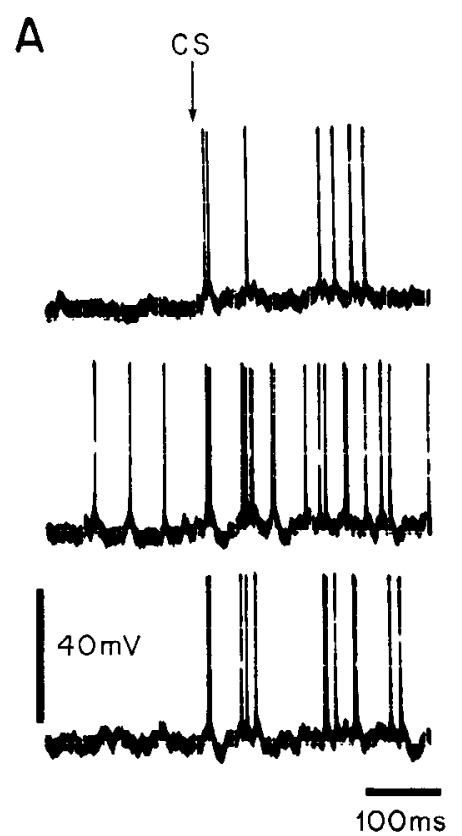

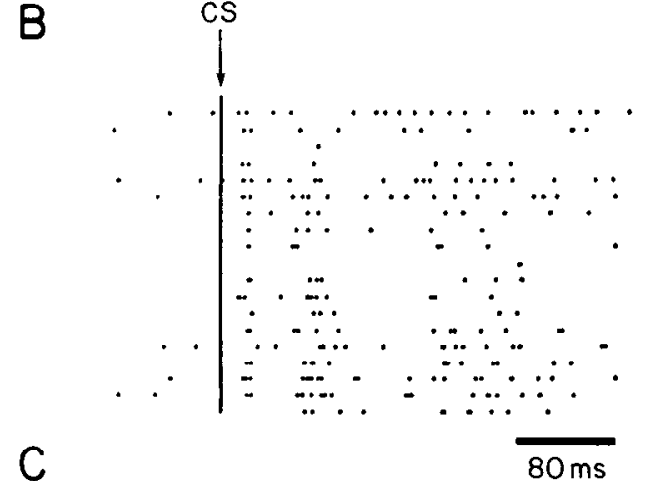

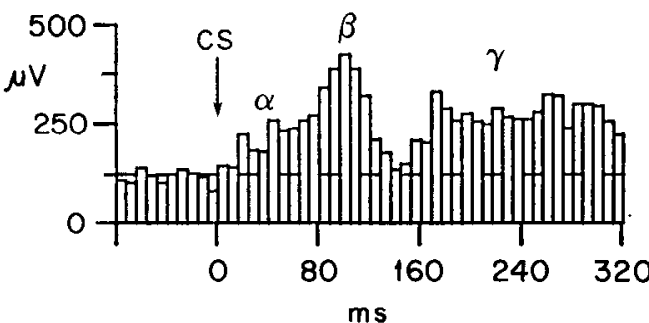

Figure 2. A, Recordings of activity from a single unit of the motor cortex of a cat conditioned to eye blink. $B, A$ dot raster is shown of spike occurrences during sequential presentations (top to bottom) of the CS, the occurrence of which is indicated by the solid vertical line. Increased periods of spike discharge were correlated with $\alpha, \beta$ and $\gamma$ periods of increased EMG activity shown in the histogram average below (C). Time and voltage calibrations are as indicated. Data in $A$ and $B$ werc obtained from the same unit. The EMG data in $C$ were obtained while recording from this unit.
Further details of the protocol used to obtain unit recordings during different behavioral states are shown in Figure 1. All comparisons of unit responses to the CS and DS made between different behavioral states were made during presentations of the CS and DS alone. No corrections were made for air conduction over the distance of 1-2 feet between the apparatus and the ears of the animals. Unit recordings were obtained before conditioning (during adaptation) in 11 cats (Table 1 , ADP) and in 5 of these cats after conditioning (COND). Studies were also made in previously conditioned cats after prolonged extinction sessions, and the data were divided into those showing extinction with retention of CR performance (Tablc 1, EXT S ${ }^{+} ; n=2$ cats; mcan, 350 trials) and those showing full extinction with loss of CR performance (EXT S; $n=3$ cats; mean, 340 trials). Retention was defined by the presence of EMG responses to the CS averaging $>3 Z$ above background activity and loss by the absence of responses averaging $>3 Z$ above background activity. Effects of backward conditioning [Del HS; see Kim et al. (1983) for reasons for calling this a "delayed" HS paradigm and for evidence of its usefulness in separating forward from backward pairing effects on behavioral conditioning] were studied in six cats of which two were previously naive (Table $1, \mathrm{DHS}_{0}$ ) and the other four were previously conditioned $\left(\mathrm{DHS}_{c}\right)$.

Most recording sessions included repeated extinction and reconditioning to allow the activity of many single units to be recorded in response to presentations of the CS and DS when the CR was performed and when it was absent or reduced. Judging by the absence of effects on neural excitability (see Aou et al., 1992), the amount of reconditioning did not appear to have much influence on the results. Additional analyses were performed early and late during partial extinction (see Fig. 3, postconditioning vs partial extinction) to evaluate changes in patterns of unit activity (and excitability; see Aou et al., 1992) due to the transition between conditioned and (partial) extinction behavioral states (Fig. 1B).

Hypothalamic stimulation. Electrical stimulation of the hypothalamus was accomplished with bipolar, stainless steel, concentric electrodes (David Kopf Instruments, NE 100). The diameters of the concentric electrodes were 0.2 and $0.5 \mathrm{~mm}$, respectively, each with an exposed tip length of $0.5 \mathrm{~mm}$. Each train of stimulation consisted of four brief rectangular pulses of $200 \mu \mathrm{sec}$ duration, presented at $50 \mathrm{~Hz}$. Currents of $0.6-5 \mathrm{~mA}$ were used with intensities adjusted to obtain optimal behavioral effects. The lateral hypothalamic region was selected as the locus of stimulation on the basis of earlier studies in which HS was used successfully to produce rapidly acquired long-latency blink CRs (Kim et al., 1983). [Preliminary findings suggest that HS may influence cortical neurons by activating a neuromodulatory transmitter system (Cooper and Woody, 1983). Also, rapid conditioning of cortical units can be accomplished by local ionophoretic application of glutamate, intracortically, in lieu of HS (Woody et al., 1991a).] Since most of the cats required electrical $\mathrm{HS}$ of $>1 \mathrm{~mA}$ intensity to learn discriminative CRs rapidly, the effects of HS were not likely to have been confined to local regions. At the end of each experiment, a steady current $(1 \mathrm{~mA}$, $20 \mathrm{sec}$ ) was delivered through the electrode in order to produce a small lesion. Animals were then killed with sodium pentobarbital and perfused with physiological saline followed by $10 \%$ formalin to confirm locations of electrodes by histologic analysis as shown in Figure $1 C$.

\section{Results}

The activity of 462 neurons on the pericruciate cortex was recorded during different behavioral states as specified in Table 1. As noted earlier, intracellularly and extracellularly recorded data were combined to make averages of the patterns of unit discharge associated with different states and with production of the blink CR. An example of activity obtained by recording intracellularly from a neuron of a conditioned cat is provided in Figure 2. This neuron showed a triphasic excitatory response to the click CS. The timing of each component of increased spike discharge (Fig. $2 B$ ) preceded corresponding $\alpha, \beta$, and $\gamma$ components of the $\mathrm{CR}$ (Fig. 2C) measured by simultaneous EMG recordings from the orbicularis oculi muscles.

\section{Averaged patterns of unit activity in naive, conditioned, and extinction states}

The activity of single units was sampled in successive $1 \mathrm{msec}$ periods and summed to form histograms of the response elicited by the click CS and hiss DS. Figure 3 shows the averages across cats (see Materials and Methods) of spike and EMG activity obtained during three different behavioral states: (1) the last five trials of adaptation, $n=11$ cats (see Fig. 1, Table 1); (2) the first five extinction trials following conditioning sessions, $n=5$ cats (postconditioning; see Fig. 1B); and (3) the last five, partial extinction trials following conditioning sessions while recording from the same cells as in state 2 (partial extinction; see Fig. $1 B$ ). Bin widths of $32 \mathrm{msec}$ were used in the histograms of Figure 3 to facilitate display of the full $1280 \mathrm{msec}$ period following CS and DS delivery.

During adaptation (state 1), a small increase in neuronal ac- 
Unit

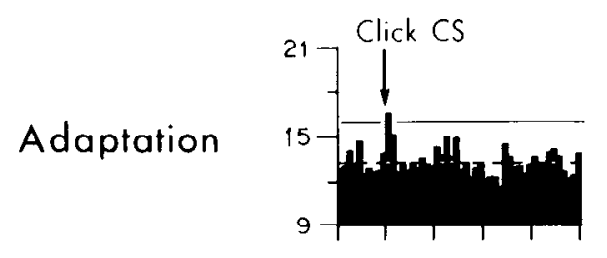

Post
Conditionin
Partial
Extinction

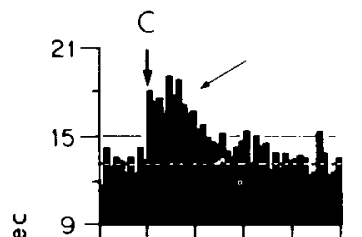

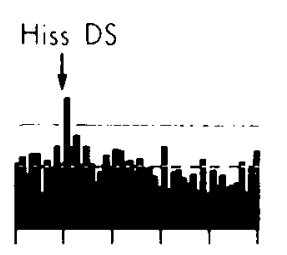
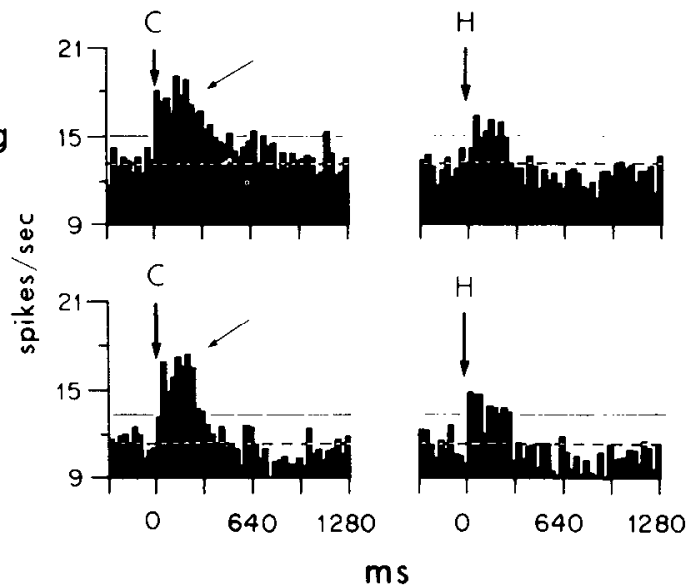
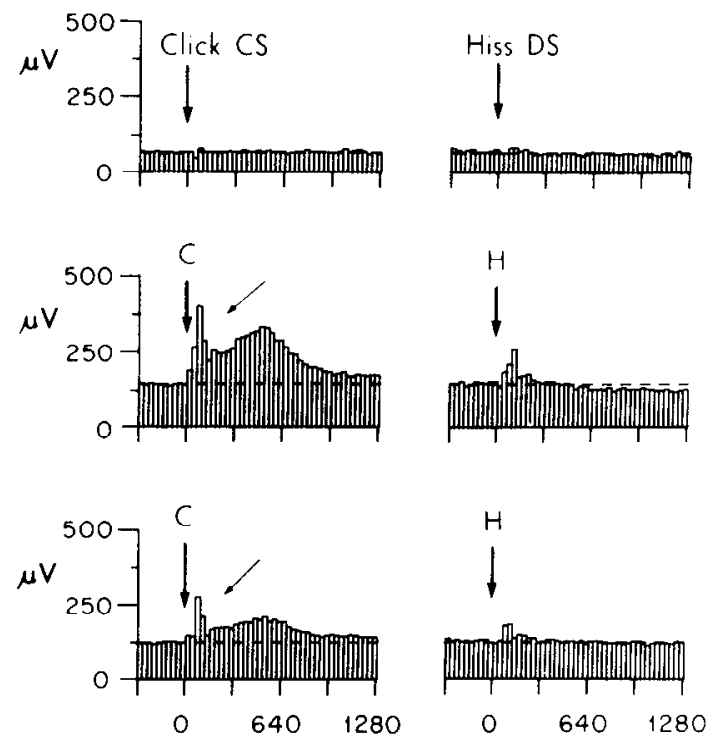

$\mathrm{ms}$

Figure 3. Histogram averages of spike activity (left, solid bars) and corresponding EMG activity (right, open bars) during different behavioral states: (1) adaptation ( $n=154$ cells), (2) the first five extinction trials after conditioning of the blink CR (postconditioning; $n=136$ cells), and (3) later extinction trials in which some CR savings were present (partial extinction; $n=136$ cells). Responses to click CS $(C)$ and hiss DS $(H)$ are as indicated. Presentations of these stimuli are given at time 0 (vertical arrows). Calibrations for spike activity (spikes/sec) and EMG activity ( $\mu \mathrm{V}$ ) are as shown. Time scale is in milliseconds. Baseline levels of spike discharge and EMG activity (broken lines) are the mean of the activity in the period from 0 to $380 \mathrm{msec}$ preceding delivery of the CS. A solid line is drawn $3 Z$ (SD) above the baseline spike activity. Diagonal arrows point to CRs. Increases in spike activity in response to the CS were closely correlated with acquisition and performance of the blink CR. A more detailed view of the early components of the response may be found in Figure 4. Data from other behavioral states, including backward conditioning, are shown in Figure 6. Each histogram of unit activity in Figures 3-7 shows a characteristic response made up from the combined averages of activity of many single units recorded in each behavioral state.

tivity above the spontaneous background firing level was seen in response to the CS and DS (Fig. 3). The response to the DS was slightly greater than that to the CS during adaptation. After conditioning (state 2), the size and duration of the averaged unit responses to the CS and DS increased. The mean response to the CS became $>3 Z$ greater (see Winer, 1971) than that to the DS, and behavioral CRs to the CS were elicited discriminatively by the CS. After partial extinction of the CR (state 3), the unit response to the CS was slightly reduced compared with that after conditioning but, with continued performance of the CR, remained elevated with respect to that seen prior to conditioning.

As secn in Figure 3, the mean rate of spontaneous firing in the conditioned state $(13.0 \pm 0.6 \mathrm{spikes} / \mathrm{sec})$ was not different from that in the naive adaptation state $(13.0 \pm 0.9 \mathrm{spikes} / \mathrm{sec})$. In the partial extinction state, the spontaneous firing rate averaged $11.2 \pm 0.6 \mathrm{spikes} / \mathrm{sec}$. The response to the CS above baseline activity remained large, and CRs were produced.

Examination of the histograms in Figure 3 suggested that unit activation preceded rather than followed elicitation of the conditioned EMG responses. EMG activation outlasted unit discharge and not vice versa (Fig. 3, EMG vs. unit histograms, postconditioning and partial extinction). Expansion of the time scales of the histograms (Fig. 4) confirmed that the onset of the unit activity in response to the CS preceded the onset of the EMG response. Figure $4 B$ shows that the onset and cumulative increase in spike activity elicited by the CS preceded initiation of the conditioned $\alpha_{1}$ motor response by approximately 7-8 msec. [This is the conduction delay expected between motor cortex, facial nucleus, and periphery (Woody and Yarowsky, 1972).] Figure $4 A$ shows that the peak of unit activity in response to the CS preceded the peak EMG response. Although the irregularity of spike discharge masked the timing of the later increases, further analyses, to be described in more detail below (Fig. 5), found spike responses with onsets corresponding to each component of the conditioned EMG response.

\section{Components of mean unit response to the $C S$ versus components of the conditioned behavioral response}

The relation of unit discharge to different components of the $\mathrm{CR}$ was examined in morc detail by classifying units recorded during adaptation and conditioning according to the onset latency of their response to the CS. Onset latencies were defined by activity (per $4 \mathrm{msec}$ ) exceeding $2 \mathrm{SD}$ above the mean of the $40 \mathrm{msec}$ period of baseline activity preceding delivery of the CS. (A 2 SD level was needed here to detect the onsets of the responses.) The periods used for classification were $8-40 \mathrm{msec}$ $\left(\alpha_{1}\right), 40-72 \mathrm{msec}\left(\alpha_{2}\right), 72-112 \mathrm{msec}(\beta)$, and 112-160 msec $(\gamma)$ after the CS. These periods were selected to precede by $8 \mathrm{msec}$ (the approximate transmission time from motor cortex to blink musculature) the related components of the conditioned EMG responses. Averages of the spike activity of units classified in this way (Fig. 5A) showed that the amplitude and duration of each component of unit activity, corresponding to the components of the $C R$, increased after conditioning.

Figure $5 B$ compares percentages of units with onset latencies 
Table 1. Numbers of cells from which recordings were obtained to permit analysis of unit activity by cat and behavioral state

\begin{tabular}{|c|c|c|c|c|c|c|}
\hline \multirow[b]{2}{*}{ Cat } & \multicolumn{6}{|c|}{ Behavioral state } \\
\hline & $\mathrm{ADP}$ & COND & EXT S $^{+}$ & EXT S $^{-}$ & $\mathrm{DHS}_{0}$ & $\overline{\mathrm{DHS}_{c}}$ \\
\hline D & $10(0)$ & - & - & - & - & - \\
\hline $\mathbf{N}$ & $35(9)$ & $20(16)$ & $21(18)$ & - & - & $11(2)$ \\
\hline$F$ & $1(1)$ & $21(18)$ & $21(18)$ & - & - & $12(11)$ \\
\hline $\mathbf{G}$ & $35(7)$ & $10(3)$ & - & - & - & - \\
\hline I & $18(0)$ & $13(0)$ & - & - & - & $3(0)$ \\
\hline $\mathrm{H}$ & $26(3)$ & $72(8)$ & - & - & - & $2(0)$ \\
\hline $\mathbf{A}$ & $2(2)$ & - & - & $21(4)^{a}$ & - & - \\
\hline B & $3(3)$ & - & - & $25(9)^{a}$ & - & - \\
\hline $\mathrm{O}$ & $8(6)$ & - & - & $17(9)^{a}$ & - & - \\
\hline $\mathrm{E}$ & $7(7)$ & - & - & - & $20(18)$ & - \\
\hline $\mathrm{C}$ & $9(6)$ & - & - & - & $19(8)$ & - \\
\hline Total $n$ & $154(44)$ & $136(45)$ & $42(36)$ & $63(22)$ & $39(26)$ & $28(13)$ \\
\hline
\end{tabular}

Numbers of cells that were recorded intracellularly are shown in parentheses; abbreviations are similar to those in Figures 1-7. Analyses were made of unit responses to click CS and hiss DS before conditioning (ADP), following successful conditioning and reconditioning of blink CRs (COND), after extinction of the CR (EXT), and following backward conditioning (DHS; data taken at same times as in COND) using a reversed order of HS pairing (Del HS paradigm; see Kim et al., 1983) in place of the forward order of CS-US-HS pairing.

${ }^{a}$ These cats were conditioned prior to extinction of the $\mathrm{CR}$.

between 0 and 40 msec post-CS during adaptation (Adap), during extinction trials with continued performance of the $C R$ (Ext $\mathrm{S}^{+}$) and during extinction without continued performance of the CR (Ext $\mathrm{S}^{-}$). Further information on the paradigms and the numbers of cells studied is given in Figure 1 and Table 2. The number of units responding in the period 16-24 msec after CS delivery was increased when there was retention of performance of the CR (Fig. 5B). (The number was also increased immediately after conditioning, but not so greatly as after prolonged extinction in the Ext $\mathrm{S}^{+}$group.)

Increases in unit activity in the period $\geq 112 \mathrm{msec}$ after the CS were found in cells with onsets of activation corresponding to each component of the CR (Fig. 5A). This suggested that activation of some cells could support production of more than one component of the conditioned response (compare Fig. 2). The increases in the late components of activity were without clear peaks at any one latency over the period of extended discharge (see Fig. $5 A$ ).

After conditioning, an inhibition of discharge was noted in the $80 \mathrm{msec}$ following CS delivery in cells with onsets of increased activity in the period 112-160 msec after the click (Fig. $5 A$ ). The low baseline firing rates of the cortical neurons prevented clearer definition of these patterns of inhibited discharge.

\section{Unit activity after extinction and backward conditioning}

Further analyses were made to characterize patterns of activity after prolonged extinction (see Fig. 1) and after backward conditioning. In these analyses (Fig. 6), the averages of unit activity were separated into data obtained from CS-responsive and CSunresponsive (or less responsive) groups of units. The numbers of cells responding to the CS and DS are shown as a function of behavioral state in Table 2 . A responsive unit was defined as one with activation of discharges $\geq 3 Z$ above (pre-CS) baseline in any $4 \mathrm{msec}$ period $0-160 \mathrm{msec}$ after presentation of the CS. The proportion of cells that responded to the CS in the
A
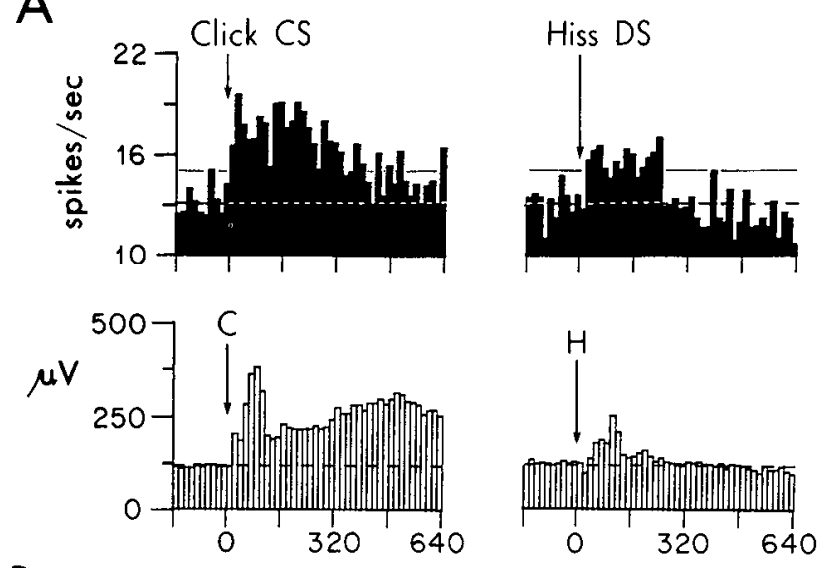

B

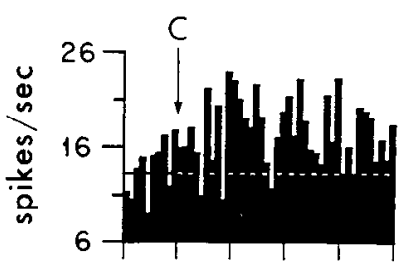

ms
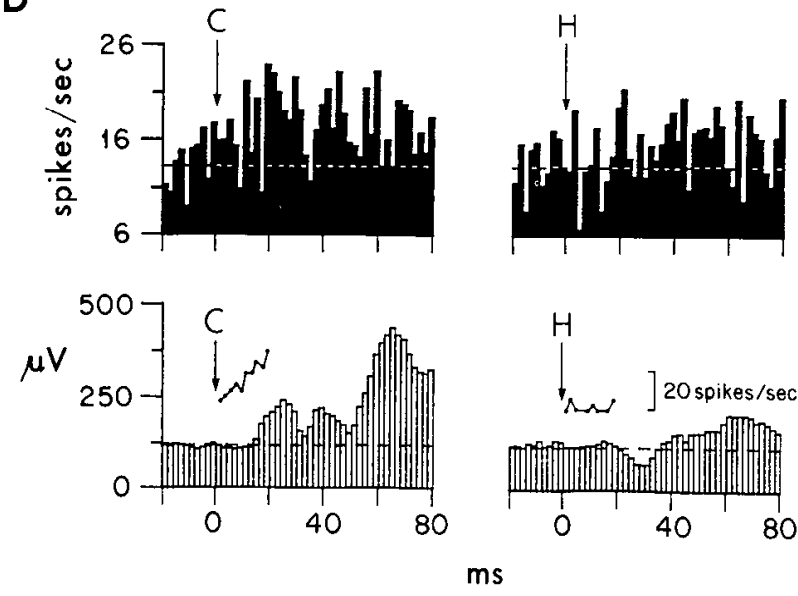

Figure 4. Histogram averages of spikc activity (solid bars) and EMG activity (open bars) in response to click CS $(C)$ and hiss DS $(H)$ after conditioning. Labels, including baseline activity (dashed line) and activity $3 Z$ above baseline (solid horizontal line), are as in Figure 3. $(A$ and $B$ are averages at different time scales of all data from the first five extinction trials following conditioning and reconditioning sessions.) Records in $A$ show peaks of unit responses (upper traces) that precede peaks of EMG responses (lower traces). Records in $B$ show cumulative increases in spike activity above baseline that precede initiation of the conditioned motor response. The thin solid lines to the right of the vertical arrows above the histograms of EMG activity are integrations of the spike activity taken from the histograms above, scale normalized to initial baseline levels of spike activity. After delivery of the CS (C), the rise in spike activity precedes the rise in EMG activity. Both EMG and spike responses are discriminative.

conditioned state $(83$ of $136,61 \%)$ was higher $\left(\chi^{\mathrm{a}}, p<0.02\right)$ than in the naive state ( 71 of $154,46 \%)$. Analyses of the histograms indicated that the response criterion of $\geq 3 Z$ above background activity identified a sufficient number of responsive cells to demonstrate characteristic responses in the averages.

Averages of activity from CS-responsive and -unresponsive units (Fig. 6) were made in each behavioral state as follows: (1) adaptation (Adap), (2) the period after conditioning (Cond) from postconditioning through partial extinction (see Fig. 1B), (3) subsequent extinction trials with learning savings (Ext $\left.S^{+}\right)$, (4) subsequent extinction trials without savings (Ext $\mathrm{S}^{-}$), (5) the period comparable to the Cond period following backward conditioning in animals that received no previous conditioning trials $\left(\mathrm{DHS}_{0}\right)$, and (6) the comparable period following backward conditioning in animals that had received previous conditioning trials with development of blink CRs $\left(\mathrm{DHS}_{c}\right.$ ). [All available 


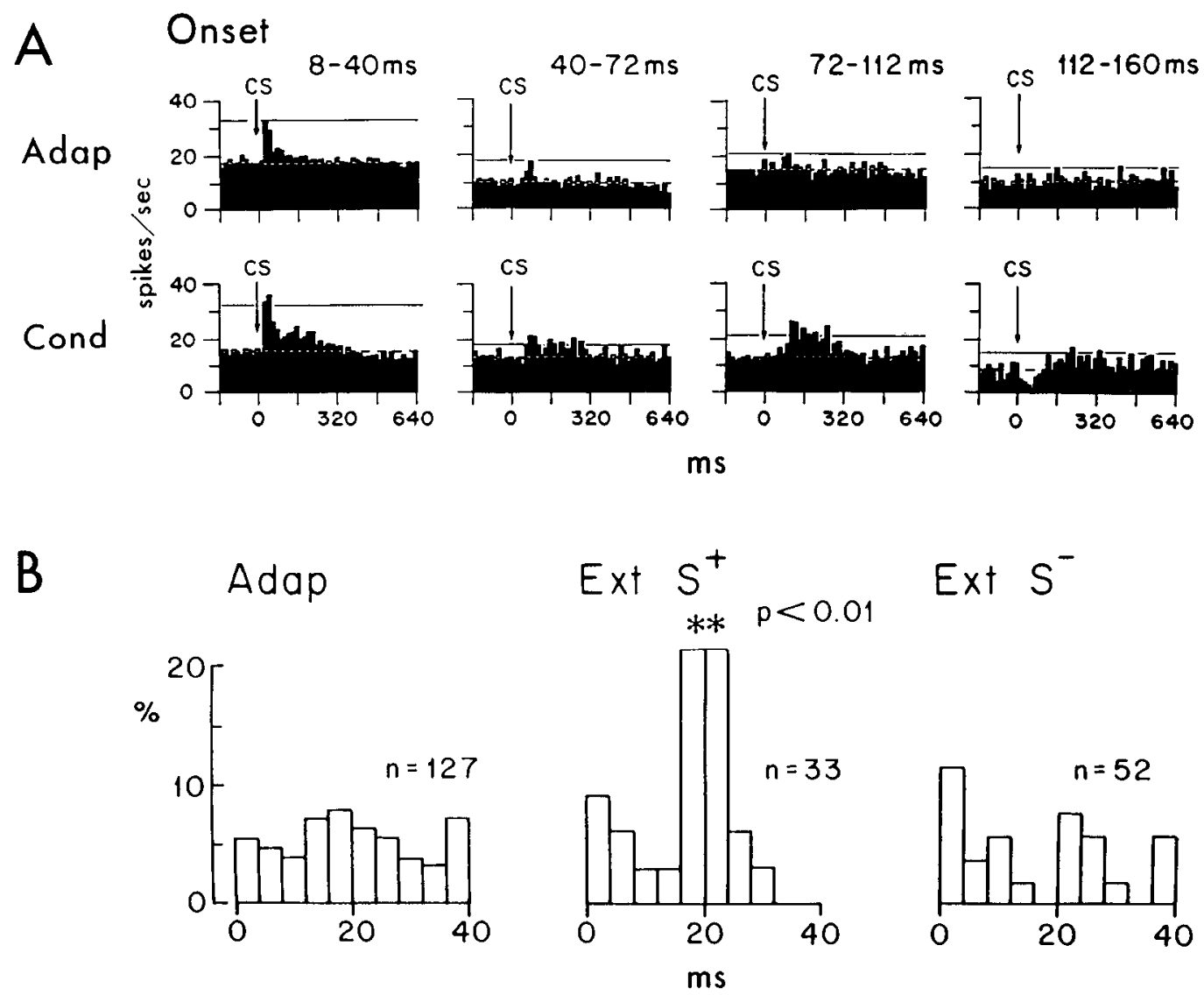

Figure 5. A, Histogram averages showing unit responses of different latencies associated with performance of blink CR (during initial extinction of the conditioning). Onset: Units were classified as responding in each latency period if first activity (per 4 msec) $>2 Z$ above baseline occurred in the period indicated $(8-40,40-72,72-112$, or $112-160 \mathrm{msec})$ following presentation of the CS. Adaptation (Adap), $n=71$ units; postconditioning (Cond), $n=83$ units. Other labeling is as in earlier figures. $B$. Percentages of cells with onsets of responses to CS $>2 Z$ above baseline activity in the period 0-40 msec after CS delivery, for three different behavioral states: Adap, Adaptation (CS + DS); Ext $S^{+}$, extinction with learning savings of CRs $\geq 3 Z$ above baseline EMG activity. Ext $S^{-}$, "full" extinction with learning savings of CRs $<3 Z$ above baseline EMG activity. $n$, number of units from which the data were compiled. The peaks labeled by asterisks are higher than those in the other behavioral states $\left(\chi^{2}\right.$ test comparing numbers of cells).

trials were included in analyses of spike activity from units in each group (Table 2).]

Each behavioral state in which performance of CRs was observed (Cond, Ext $\mathrm{S}^{+}$, and $\mathrm{DHS}_{c}$ ) showed discriminative unit responses to the CS (see Fig. 6). Although CS-responsive cells were identified without regard to whether the onset of increased

Table 2. Percentage (\%) and number ( $n$ ) of CS- and DS-responsive cells (activity $\geq 3 Z$ above baseline in any 4 msec period from 0 to 160 msec after click and hiss, respectively) and unresponsive cells (activity $<3 Z$ above baseline) as a function of behavioral state

\begin{tabular}{llllll} 
& \multicolumn{5}{l}{ Cells } \\
\cline { 2 - 6 } State & $\mathrm{B}(\% / n)$ & $\mathrm{C}(\% / n)$ & $\mathrm{H}(\% / n)$ & $0(\% / n)$ & Total \\
\hline ADP & $27 / 42$ & $19 / 29$ & $16 / 25$ & $38 / 58$ & 154 \\
COND & $38 / 52$ & $23 / 31$ & $16 / 22$ & $23 / 31$ & 136 \\
EXT S$^{-}$ & $21 / 13$ & $29 / 18$ & $14 / 9$ & $36 / 23$ & 63 \\
EXT S$^{+}$ & $40 / 17$ & $17 / 7$ & $19 / 8$ & $24 / 10$ & 42 \\
DHS $_{0}$ & $36 / 14$ & $23 / 9$ & $8 / 3$ & $33 / 13$ & 39 \\
DHS $_{c}$ & $32 / 9$ & $14 / 4$ & $14 / 4$ & $40 / 11$ & 28
\end{tabular}

Cells: B, responsive to both click and hiss; $C$, response to click only; $H$, responsive to hiss only; 0 , unresponsive to click or hiss. State: defined as in Table 1. activity preceded or followed the onset of the blink, the patterns of discharge of these cells reflected the multiple components of the CR and had earlier onsets than the movements. The increases in discharge elicited by the CS persisted through prolonged extinction sessions with savings of performance of the CR (Fig. 6, Ext S+). With full extinction of the conditioned blink response (Ext $\mathrm{S}^{-}$), the unit response to the CS was reduced and did not exceed $3 Z$ above the baseline activity. This behavioral state (Fig. 6, Ext $\mathrm{S}^{-}$) showed a particularly pronounced reduction of the short-latency components of unit discharge in response to the CS.

In animals given backward conditioning without any prior conditioning sessions, unit activity in response to the CS was not increased above levels found during adaptation (Fig. 6, Adap vs. $\mathrm{DHS}_{0}$ ). In animals that received Del HS after previous conditioning of blink CRs, the spike response to the CS was large (Fig. 6, DHS $)$. Patterns of both spike and EMG activity in response to click CS in the $\mathrm{DHS}_{c}$ animals were consistent with a sensitization of the previously conditioned response.

The spontaneous activity of CS-responsive units (Fig. 6) was much the same as that of CS-unresponsive units during adaptation and conditioning. (There was no increase in spontaneous rates of discharge in CS-responsive or -unresponsive cells after 


\section{CS RESPONSIVE}

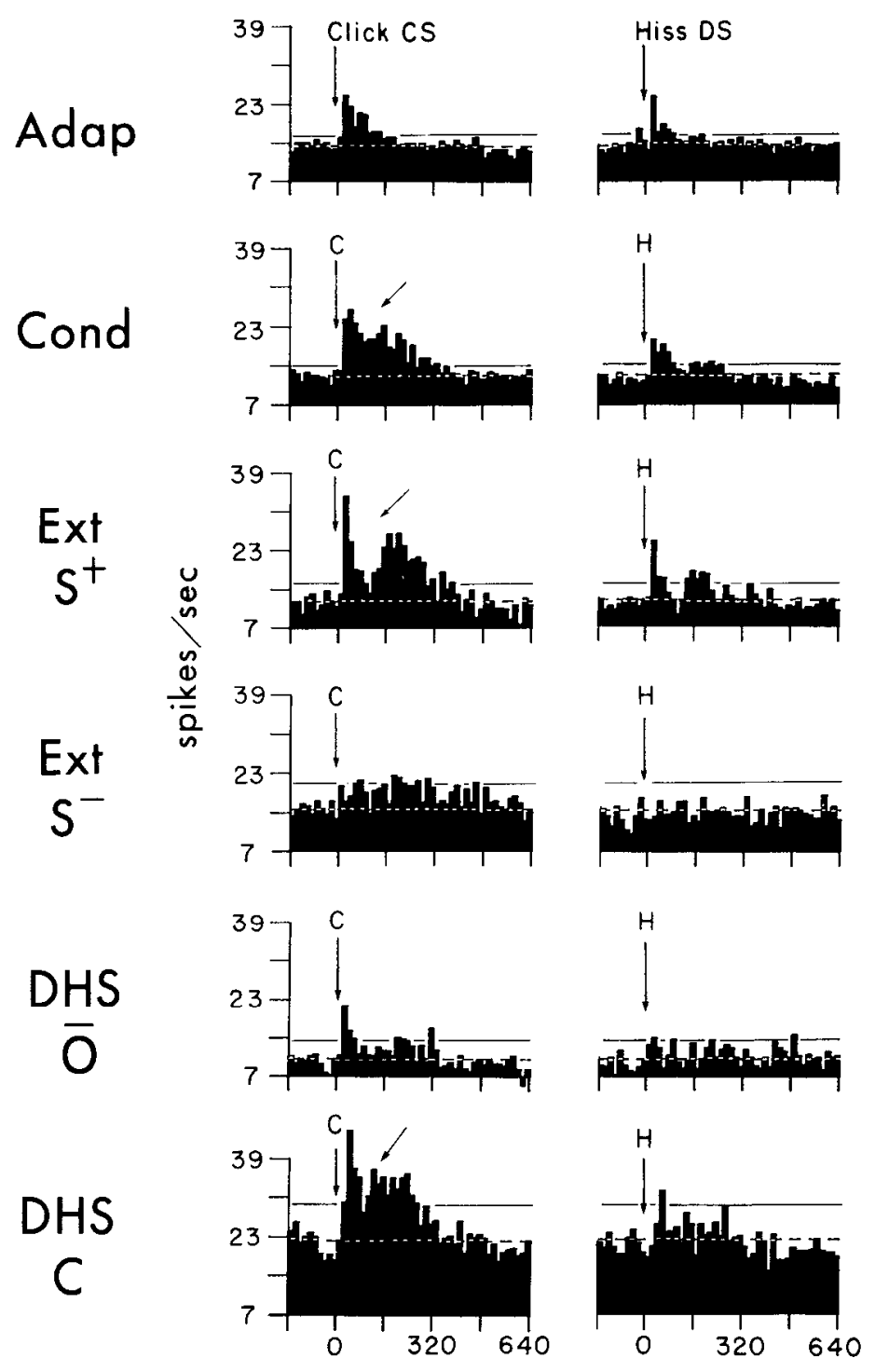

\section{CS UNRESPONSIVE}
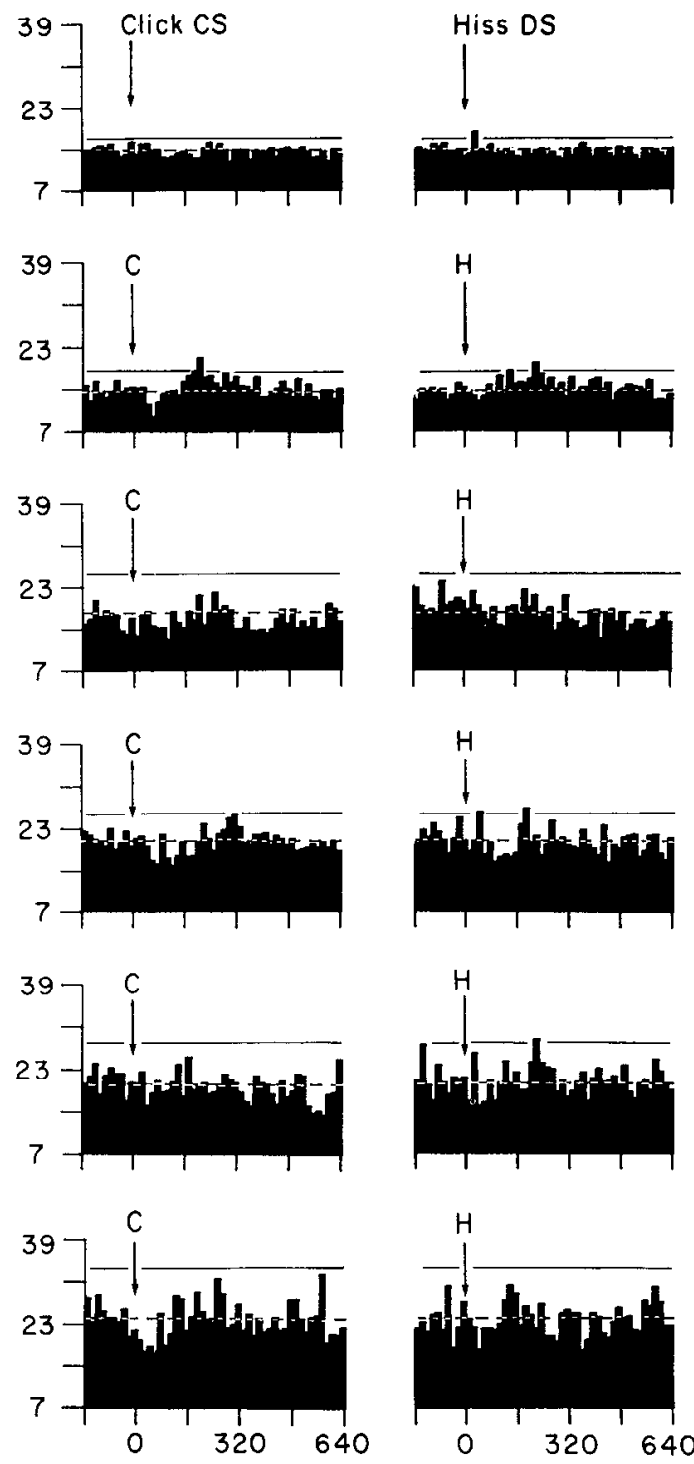

$\mathrm{ms}$

Figure 6. Histogram averages of activity of units separated according to response to the CS. (Response defined by activity in any period from 0 to $160 \mathrm{msec}$ after CS delivery $>3 Z$ above baseline preceding CS delivery.) Solid horizontal lines show $3 Z$ levels; broken lines show spontaneous, baseline activity. Unit activity is shown for different behavioral states: adaptation (Adap), initial extinction after conditioning of blink CR (Cond), extinction trials in which CR savings were present $\left(E x t S^{+}\right)$, extinction trials in which no CRs occurred (Ext $\left.S^{-}\right)$, extinction following presentations of Del HS paradigm in which there were no previous conditioning trials $\left(D H S_{0}\right)$, and extinction following presentations of Del HS paradigm in which there were previous conditioning trials with development of blink CR $\left(D H S_{c}\right)$. Diagonal arrows show histograms that were associated with sustained conditioned behavioral responses. Other labeling is as in previous figures. The numbers of cells analyzed are shown in Table 2.

conditioning compared with rates during adaptation.) An increase in spontaneous activity was observed in the CS-unresponsive cells during prolonged extinction. This increase was greater when the performance of the CR was reduced (Ext $\mathrm{S}^{-}$) than when not (Ext $S^{+}$). During Del HS without previous conditioning, CS-unresponsive cells also showed a higher level of averaged spontaneous activity than did CS-responsive cells (Fig. 6). Spontaneous activity of CS-responsive cells increased in animals given backward conditioning after prior conditioning sessions with development of a blink $\mathrm{CR}$, and the activity of CSunresponsive cells was also elevated.

\section{Activity of $C S$-versus $D S$-responsive cells}

To evaluate activity as a function of unit receptivity in more detail, units were divided into units responding to click alone, units responding to hiss alone, units responding to both click and hiss, and units that failed to respond to either click or hiss (Table 2, Fig. 7). Responsiveness to the CS and DS was defined, as earlier, by activation of discharges $\geq 3 Z$ above baseline in the period $0-160 \mathrm{msec}$ after presentation of the CS or DS, respectively.

A comparison of the activity of each group of cells was made 


\section{Click}

\section{Cond}

Ext

$\mathrm{S}^{+}$

DHS

C
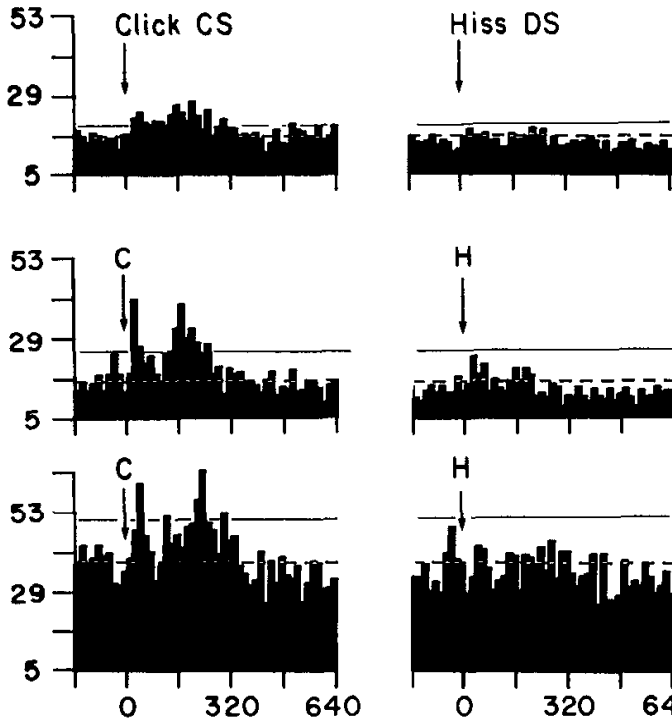

ֻัญ

Cond
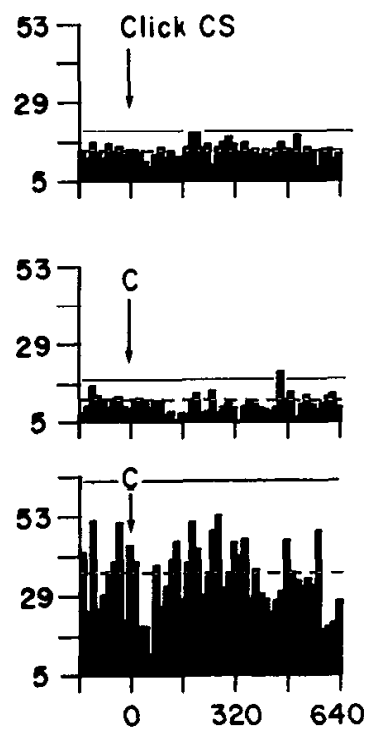

Hiss
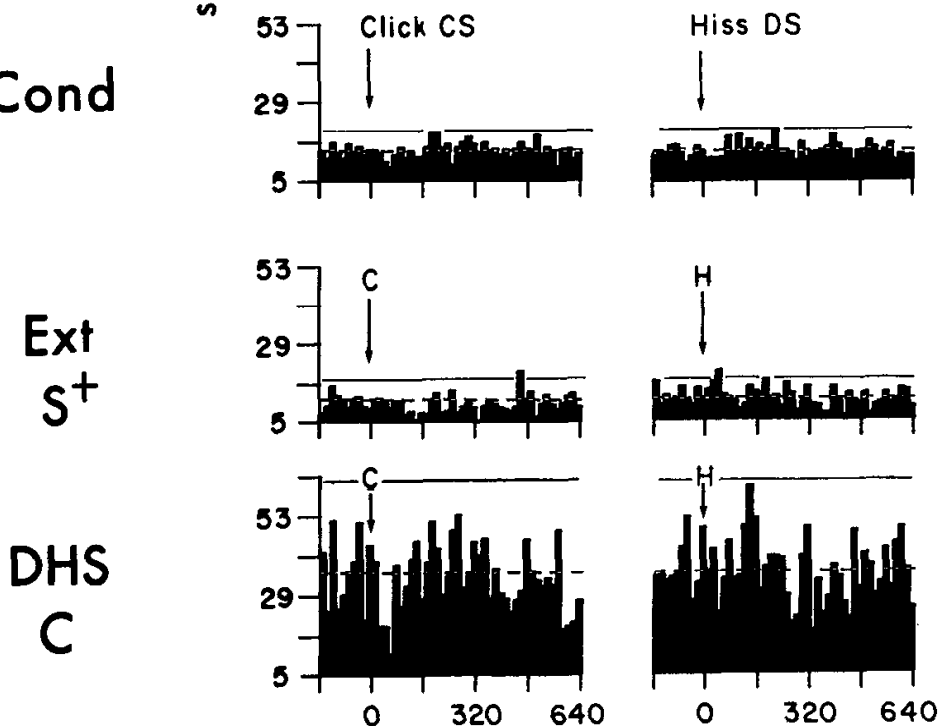
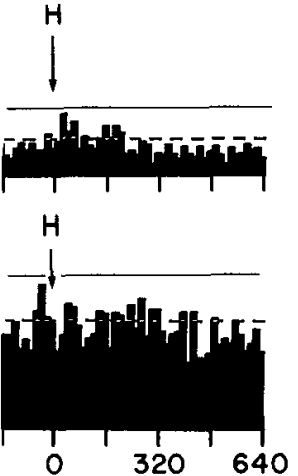

\section{$\mathrm{ms}$}
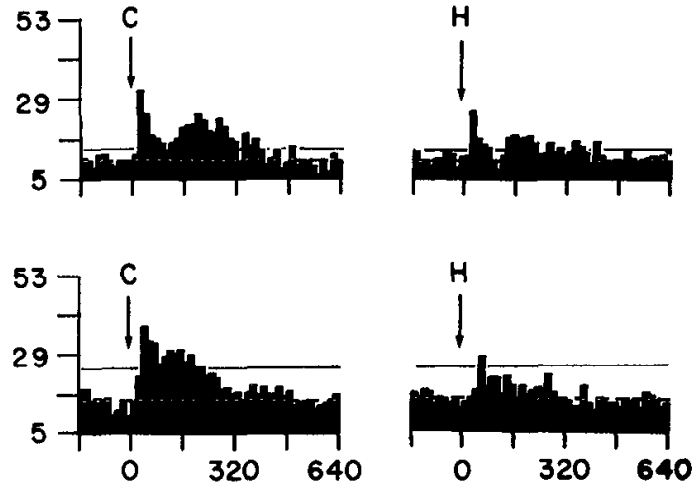
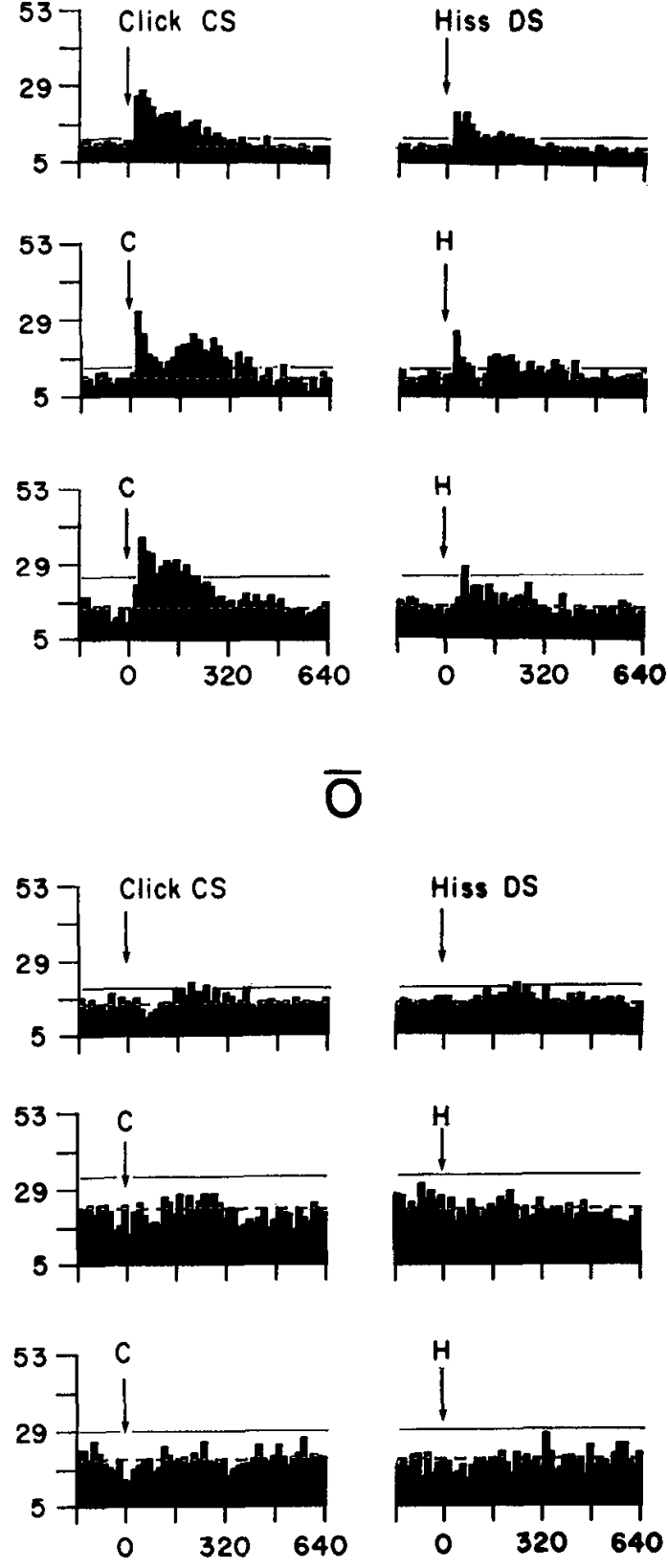

ms

Figure 7. Histogram averages of activity of units in Figure 6 separated according to units responding only to click CS (Click), to both click CS and hiss DS (Both), only to hiss DS (Hiss), and to neither click CS nor hiss DS (O). Data are shown from behavioral states during which CRs were present: extinction after initial conditioning of blink CR (Cond), extinction in which CR savings were present (Ext $\left.S^{+}\right)$, and extinction following presentations of Del HS paradigm in which there were previous conditioning trials with development of blink CR $\left(D H S_{c}\right)$.

for each behavioral state in which CRs were consistently elicited by the CS (Fig. 7). Click-responsive cells and "both"-responsive cells showed sizeable unit discharges in response to the CS, while hiss-responsive cells showed only wcak responses to hiss DS. This was consistent with discriminative elicitation of the $\mathrm{CR}$ by the CS and not the DS. The ratio of CS-evoked activity to background activity was greater in the cells that were responsive to both click and hiss, and the response was discriminative in that group as well as in the cells that responded to click alone. Increased levels of spontaneous activity were found in click- responsive cells and hiss-responsive cells of animals that received backward conditioning after prior blink conditioning (DHS $)_{c}$.

\section{Discussion}

The activity elicited by a click CS in units of the motor cortex of cats increased relative to that elicited by a hiss DS after rapid conditioning of a compound eye blink reflex (Fig. 3). Unit activity in response to click was not comparably altered after backward conditioning (Fig. 6, DHS $_{0}$ ) with HS preceding click 
and tap. Backward conditioning was ineffective in producing sustained CRs.

The rapidly conditioned blink CR used in these studies had more components than did previous blink CRs acquired after use of the same CS and US without HS (Woody and Brozek, 1969) or with addition of HS at a different ISI (Kim et al., 1983; Woody et al., 1983; cf. Voronin and Ioffe, 1974; Voronin et al., 1975). (The CRs produccd by pairing click CS and tap US had short-latency components; those produced by adding HS had long-latency components.) Use of an ISI of $570 \mathrm{msec}$ between click CS and tap US plus HS (as opposed to an ISI of 200-400 msec) facilitated production of multiple components of the CR (Hirano et al., 1987).

\section{Patterns of unit activity related to different components of the} blink $C R$

Short-, intermediate-, and long-latency components of the blink CR had counterparts in the patterns of discharge elicited by the click CS in the cortical cells. When classified according to onsets of response activity, components of unit discharge were found with onsets between $8-40 \mathrm{msec}\left(\alpha_{1}\right), 40-72 \mathrm{msec}\left(\alpha_{2}\right), 72-112$ msec $(\beta)$, and $>112 \mathrm{msec}$ ( $\gamma$ latency) following presentation of the click CS. A fifth response component could be observed after conditioning that showed a decrease in unit activity in the $80 \mathrm{msec}$ following delivery of the CS. It was conspicuous in neurons showing increased activity in the period $112-160 \mathrm{msec}$ after CS presentation (Fig. 5A). Many single units were found in which activity elicited by the CS was correlated with more than one component of the blink CR (Figs. 2, 5A).

Each latency period of the unit response exhibited conditioning-dependent increases in CS-evoked activity relative to the activity found in naive animals. The changes were characterized by (1) an increase in the magnitude of discharge elicited by the $\mathrm{CS},(2)$ an increase in the proportion of units found to respond to the CS, and (3) an increase in the (signal-to-noise) ratio of CS elicited activity to background activity. These increases in CS-evoked unit activity after rapid eye blink conditioning resembled changes in activity found earlier with slower conditioning of a simpler blink response using the same click CS and tap US without associated HS (Engel and Woody, 1972). Thus, it seemed unlikely that the rapidly acquired CRs represented a substantially different form of conditioning than the more slowly acquired form.

\section{Control of initiation of movement}

Our findings support the hypothesis that the motor cortex controls the initiation of conditioned movements of both short and long latency. Earlier studies have noted that neurons of the cat motor cortex become active before movement onset (e.g., Woody and Engel, 1972; Vicario et al., 1983; Martin and Ghez, 1985) and respond to auditory stimuli at short latencies (Sakai and Woody 1980). In the present study, activation of unit discharge by the CS preceded rather than followed the onsets of the conditioned EMG responses. Cumulative increases in CS-evoked spike activity preceded initiation of the conditioned $\alpha_{1}$ motor responsc by approximately $7-8 \mathrm{msec}$ (Fig. $4 B$ ), the delays appropriate for transmission between cortex and periphery (Woody and Brozek, 1969; Woody and Yarowsky, 1972). Since EMG activation outlasted the unit response (Fig. 3), the conditioned movement apparently contributed little to the pattern of cortical unit activity elicited by the CS.

Much the same patterns of unit response to the CS were associated with performance of the blink CR early and late during partial extinction when performance of the CR was retained. After prolonged extinction, when the $C R$ was not performed, the CS-responsive units showed a reduction of response consistent with decreased performance of the CR. The CS-unresponsive (or less responsive) units showed an increased rate of background firing. This increase in activity was associated with behavioral states that produced a suppression of CRs. Cells with little or no response to the CS may therefore play a role in active inhibition of CR performance, for example, through descending inhibitory pathways to motoneurons (Asanuma and Sakata, 1967; Sauerland et al., 1967a,b; Jankowska et al., 1976). Cells of the motor cortex that are not auditory responsive tend to be of different morphologic type than those that respond at short latencies to click (Sakai and Woody, 1980). The differences between CS-responsive and -unresponsive cells may thus reflect differences between types of cortical cells and their pathways.

\section{Spontaneous firing}

Although enhancement of background firing activity has been reported by several authors to be caused by conditioning procedures (Vasillevsky and Trubachev, 1969; O'Brien et al., 1973), rates of spontaneous (baseline) unit discharge were not increased by the present conditioning paradigm. This was consistent with previous findings for the slowly acquired, short-latency eye blink CR using the same click CS and tap US (Woody et al., 1970; Woody and Engel, 1972). Given the close coupling between the activity of these cortical units and peripheral muscle contraction (Woody and Black-Cleworth, 1973; Fetz and Finocchio, 1975; Aou et al., 1992), an increased rate of spontaneous discharge could lead to unwanted muscle contraction and would not serve to support learning mechanisms that needed to be invoked repeatedly over the lifetime of the organism.

Spontaneous activity of CS-responsive and -unresponsive cells (Fig. 6) was increased in cats that received the Del HS paradigm after earlier conditioning of a blink CR $\left(\mathrm{DHS}_{c}\right)$, and the activity of CS-unresponsive units was increased after prolonged extinction and after backward stimulus presentations $\left(\mathrm{DHS}_{0}\right)$ without previous conditioning. The behavioral significance of these changes is unclear.

\section{Discriminative response to the $C S$}

In cells separated according to their ability to respond to click CS or hiss DS, there was a selective increase in the magnitude of response to the CS and not to the DS after conditioning (Fig. 7). There was also an increase in the number of cells responding to the CS. An increased number of responsive cells with an increased magnitude of response would support discriminative elicitation of the CR by the CS. Interestingly, in cells that were responsive to both click and hiss, the response to click CS was much larger than that to the hiss DS after conditioning (Fig. 7, Both). This suggested that a change presynaptic to these cells or a local change affecting primarily CS-activated synaptic conductances mediated this effect. Some responses in the motor cortex, such as the increase in numbers of CS-responsive cells and the selectively increased response to the CS in CS + DSresponsive cells, could reflect alterations originating in the auditory association cortex (cf. Woody et al., 1976) or rostral thalamus (Woody et al., 1991b).

The forms of coding and processing represented by the changes in activity in motor cortex differed from those serving discrimination of similar stimuli in more posterior, cortical auditory 
areas. In the motor cortex, the number of cells responding to the CS and magnitude of response increased after blink conditioning, but the rate of baseline activity remained unchanged (Engel and Woody, 1972). In the auditory association cortex, the number of cells responding to the CS did not increase, but both baseline activity and the magnitude of response to the CS increased (Woody et al., 1976). In the rostral thalamus, the magnitude of activity in response to the CS increased, as did the number of cells responding to the CS, while the baseline activity slightly decreased (Woody et al., 1991).

\section{Neuroanatomical representation of mediation of blink $C R S$}

Of considerable interest (Woody et al., 1970, 1974; Woody and Yarowsky, 1972; McCormick and Thompson, 1984; Yeo et al., 1984; Desmond and Moore, 1986; Thompson, 1986; Mauk and Thompson, 1987) is which neuronal pathways are involved in the development of short- and long-latency blink CRs. Conditioning-related changes in unit activity in response to auditory stimuli used as CS have been reported at many levels of the nervous system (Olds et al., 1972; Oleson et al., 1975; Disterhoft and Stuart, 1976, 1977; Gabriel et al., 1976; Woody et al., 1976; Kitzes et al., 1978; Ryugo and Weinberger, 1976; Weinberger, 1980, 1982; Birt and Olds, 1981; McCormick and Thompson, 1984; Berthier and Moore, 1986, 1990; Desmond and Moore, 1986). The behavioral model of short-latency eye blink conditioning, in which relatively simple neural circuits may be involved, provides an opportunity for elucidating the primary circuitry mediating this type of conditioning. The short latencies of response of many cells of the motor cortex to the CS suggest that neurons of this region are likely to lie along this primary pathway (Sakai and Woody, 1980).

Lesions of the pericruciate cortex prevent development of the short-latency eye blink CR produced by pairing click CS and tap US without added stimulation of the hypothalamus (Woody et al., 1974). Direct electrical stimulation of the motor cortex can be substituted for the click CS to produce a similar CR after pairing with tap US (Woody and Yarowsky, 1972). Thus, the motor cortex with its descending projections appears to be both necessary and sufficient for the formation of short-latency blink CRs.

Generation of long-latency components of conditioned blink movements is thought to depend on cerebellar and subcerebellar circuitry in brain-lesioned rabbits (Thompson et al., 1984; Yeo et al., 1984). Our results suggest that activity supporting initiation of these later components may also be generated in the intact cortical circuitry of awake cats. This may not represent simply a difference between species. Although decerebrated rabbits show some retention of a previously conditioned eyelid response, the amplitude of the conditioned response is reduced after decerebration (Mauk and Thompson, 1987). The results support the hypothesis that neurons of the motor cortex may play a role in initiating both short- and long-latency conditioned blink movements, the latter by addressing neurons in the red nucleus, cerebellum, and subcerebellar nuclei that control patterned performance of the longer response.

\section{References}

Aou S, Woody CD, Birt D (1992) Increases in excitability of neurons of the motor cortex of cats after rapid acquisition of eye blink conditioning. J Neurosci 12:560-569.

Asanuma H, Sakata H (1967) Functional organization of a cortical efferent system examined with focal depth stimulation in cats. J Neurophysiol 30:35-54.
Berthier NE, and Moore JW (1986) Cerebellar Purkinje cell activity related to the classically conditioned nictitating membrane response. Exp Brain Res 63:341-350.

Berthier NE, Moore JW (1990) Activity of deep cerebellar nuclear cells during classical conditioning of the nictitating membrane response in rabbits. Exp Brain Res 83:44-54.

Birt D, Olds M (1981) Associative response changes in lateral midbrain tegmentum and medial geniculate during differential appetitive conditioning. J Neurophysiol 46:1039-1055.

Cooper PH, Woody CD (1983) Effects of L-glutamate and L-glutamic acid diethyl ester (GDEE) on the response of cortical units to hypothalmic stimulation. Soc Neurosci Abstr 9:330

Desmond JE, Moore JW (1986) Dorsolateral pontine tegmentum and the classically conditioned nictitating membrane response: analysis of CR-related single-unit activity. Exp Brain Res 65:59-74.

Disterhoft JF, Stuart DK (1976) Trial sequence of changed unit activity in auditory system of alert rat during conditioned response acquisition and extinction. J Ncurophysiol 39:266-281.

Disterhoft JF, Stuart DK (1977) Differentiated short latency response increases after conditioning in inferior colliculus neurons of alert rat. Brain Res 130:315-333.

Engel J Jr, Woody CD (1972) Effects of character and significance of stimulus on unit activity at coronal-pericruciate cortex of cat during performance of conditioned motor response. J Neurophysiol 35:220 229.

Evarts EV (1981) Functional studies of the motor cortex. In: The organization of the cerebral cortex (Schmitt FO, Worden FG, Adelman G, Dennis SG, eds), pp 199-236. Cambridge, MA: MIT Press.

Fetz EE, Finocchio DV (1975) Correlations between activity of motor cortex cells and arm muscles during operantly conditioned response patterns. Exp Brain Res 23:217-240.

Gabriel M, Miller JD, Saltwick SE (1976) Multiple unit activity of the rabbit medial geniculate nucleus in conditioning, extinction, and reversal. Physiol Psychol 4:124-134.

Georgopoulos AP, Kettner RE, Schwartz AB (1988) Primate motor cortex and free arm movements to visual targets in three-dimensional space. II. Coding of the direction of movement by a neuronal population. J Neurosci 8:2928-2937.

Hirano T, Woody C, Birt D, Aou S, Miyake J, Nenov V (1987) Pavlovian conditioning of discriminatively elicited eyeblink responses with short onset latency attributable to lengthened interstimulus intervals. Brain Res 400:171-175.

Jankowska E, Padel Y, Tanaka R (1976) Disynaptic inhibition of spinal motoneurones from the motor cortex in the monkey. J Physiol (Lond) 258:467-487.

Kim EH-J, Woody CD, Berthier NE (1983) Rapid acquisition of conditioned eye blink responses in cats following pairing of an auditory CS with glabella tap US and hypothalamic stimulation. J Neurophysiol 49:767-779.

Kitzes LM, Farley GR, Starr A (1978) Modulation of auditory cortex unit activity during the performance of a conditioned response. Exp Neurol 62:678-697.

Martin JH, Ghez C (1985) Task-related coding of stimulus and response in cat motor cortex. Exp Brain Res 57:427-442.

Mauk MD, Thompson RF (1987) Retention of classically conditioned eyelid responses following acute decerebration. Brain Res 403:89-95.

McCormick DA, Thompson RF (1984) Neuronal responses of the rabbit cerebellum during acquisition and performance of a classically conditioned nictitating membrane-eyelid response. J Neurosci 4:28112822.

Naito H, Nakamura K, Kurosaki T, Tamura Y (1969) Precise location of fast and slow pyramidal tract cells in cat sensorimotor cortex. Brain Res 14:237-239.

O'Brien JH, Packham SC, Brunnhoelzl WW (1973) Features of spike train related to learning. J Neurophysiol 36:1051-1061.

Olds J, Disterhoft JF, Segal M, Kornblith CL, Hirsh R (1972) Learning centers of rat brain mapped by measuring latencies of conditioned unit responses. J Neurophysiol 35:202-219.

Oleson TD, Ashe JH, Weinberger NM (1975) Modification of auditory and somatosensory system activity during pupillary conditioning in the paralyzed cat. J Neurophysiol 38:1114-1139.

Ryugo DK, Weinberger NM (1976) Different plasticity of morphologically distinct neuron populations in the medial geniculate body of the cat during classical conditioning. Soc Neurosci Abstr 2:435.

Sakai H, Woody CD (1980) Identification of auditory responsive cells 
in coronal-pericruciate cortex of awake cats. J Neurophysiol 44:223231.

Sauerland EK, Knauss T, Nakamura Y, Clemente CD (1967a) Inhibition of monosynaptic and polysynaptic reflexes and muscle tone by electrical stimulation of the cerebral cortex. Exp Neurol 17:159-171.

Sauerland EK, Nakamura Y, Clemente CD (1967b) The role of the lower brain stem in cortically induced inhibition of somatic reflexes in the cat. Brain Res 6:164-180.

Snider RS, Niemer WT (1961) Stereotaxic atlas of the cat brain. Chicago: University of Chicago.

Thompson RF (1986) The neurobiology of learning and memory. Science 233:941-947.

Thompson RF, Clark GA, Donegan NH, Lavond DG, Lincoln JS, Madden John IV, Mamounas LA, Mauk MD, McCormick DA, Thompson JK (1984) Neuronal substrates of learning and memory: a "multipletrace" view. In: Neurobiology of learning and memory (Lynch G, McGaugh J, Weinberger N, eds), pp 137-164. New York: Guilford.

Vasillevsky NN, Trubachev VV (1969) Neuronal mechanisms of the temporary connexion. Electroencephalog Clin Neurophysiol 27:447448.

Vicario DS, Martin JH, Ghez C (1983) Specialized subregions in the cat motor cortex: a single unit analysis in the behaving animal. Exp Brain Res 51:351-367.

Voronin LL, Ioffe SV (1974) Changes in unit postsynaptic responses at sensorimotor cortex with conditioning in rabbits. Acta Neurobiol Exp (Wars $\iota)$ 34:505-513.

Voronin LL, Gerstein GL, Kudryashov IE, Ioffe SV (1975) Elaboration of a conditioned reflex in a single experiment with simultaneous recording of neural activity. Brain Res 92:385-403.

Weinberger NM (1980) Neurophysiological studies of learning in association with the pupillary dilation conditioned reflex. In: Neural mechanisms of goal-directed behavior and learning (Thompson RF, Hicks LH, Shvyrkov VB, eds), pp 241-261. New York: Academic.

Weinberger NM (1982) Effects of conditioned arousal on the auditory nervous system. In: The neural basis of behavior (Beckman AL, ed), pp 63-91. Jamaica, NY: Spectrum.

Winer BJ (1971) Statistical principles in experimental design, 2d ed. New York: McGraw.

Wise SP, Desimone R (1988) Behavioral neurophysiology: insights into seeing and grasping. Science 242:736-741.

Woody C, Yarowsky P, Owens J, Black-Cleworth P, Crow T (1974)
Effect of lesions of cortical motor areas on acquisition of conditioned eye blink in the cat. J Neurophysiol 37:385-394.

Woody CD (1982) Memory, learning, and higher function: a cellular view, pp 1-483. New York: Springer.

Woody CD, Black-Cleworth P (1973) Differences in excitability of cortical neurons as a function of motor projection in conditioned cats. J Neurophysiol 36:1104-1116.

Woody CD, Brozek G (1969) Changes in evoked responses from facial nucleus of cat with conditioning and extinction of an eye blink. $J$ Neurophysiol 32:717-726.

Woody CD, Engel J Jr (1972) Changes in unit activity and thresholds to electrical microstimulation at coronal-pericruciate cortex of cat with classical conditioning of different facial movements. J Neurophysiol 35:230-241.

Woody CD, Yarowsky PJ (1972) Conditioned eye blink using electrical stimulation of coronal-precruciate cortex as conditional stimulus. J Neurophysiol 35:242-252.

Woody CD, Vassilevsky NN, Engel J Jr (1970) Conditioned eye blink: unit activity at coronal-precruciate cortex of the cat. J Neurophysiol 33:851-864.

Woody CD, Knispel JD, Crow TJ, Black-Cleworth PA (1976) Activity and excitability to electrical current of cortical auditory receptive neurons of awake cats as affected by stimulus association. J Neurophysiol 39:1045-1061.

Woody CD, Kim EH-J, Berthier NE (1983) Effects of hypothalamic stimulation on unit responses recorded from neurons of sensorimotor cortex of awake cats during conditioning. J Neurophysiol 49:780791.

Woody CD, Gruen E, McCarley K (1984) Intradendritic recording from neurons of motor cortex of cats. J Neurophysiol 51:925-938.

Woody CD, Gruen E, Birt D, (1991a) Changes in membrane currents during Pavlovian conditioning of single cortical neurons. Brain Res 539:76-86.

Woody CD, Gruen E, Melamed O, Chizhevsky V (1991b) Patterns of unit activity in the rostral thalamus of cats related to short-latency discrimination between different auditory stimuli. J Neurosci 11:4858.

Yeo CH, Hardiman MJ, Glickstein M (1984) Discrete lesions of the cerebellar cortex abolish the classically conditioned nictitating membrane response of the rabbit. Behav Brain Res 13:261-266. 